
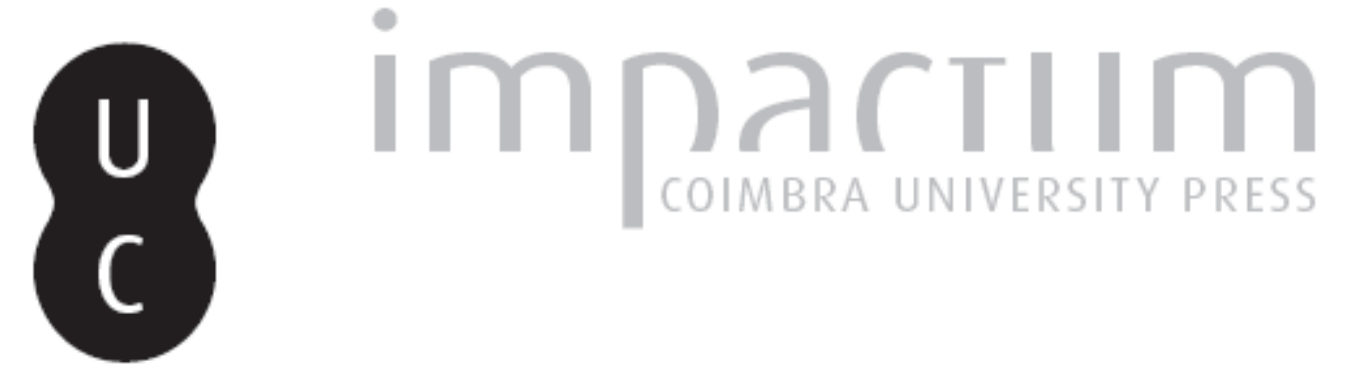

\title{
Financiamento público à I\&D empresarial em Portugal
}

\section{Autor(es): $\quad$ Carvalho, Adão}

Publicado por: Faculdade de Economia da Universidade de Coimbra

URL persistente:

URI:http://hdl.handle.net/10316.2/25242

DOI:

DOI:http://dx.doi.org/10.14195/2183-203X_37_7

Accessed : $\quad$ 26-Apr-2023 13:54:42

A navegação consulta e descarregamento dos títulos inseridos nas Bibliotecas Digitais UC Digitalis, UC Pombalina e UC Impactum, pressupõem a aceitação plena e sem reservas dos Termos e Condições de Uso destas Bibliotecas Digitais, disponíveis em https://digitalis.uc.pt/pt-pt/termos.

Conforme exposto nos referidos Termos e Condições de Uso, o descarregamento de títulos de acesso restrito requer uma licença válida de autorização devendo o utilizador aceder ao(s) documento(s) a partir de um endereço de IP da instituição detentora da supramencionada licença.

Ao utilizador é apenas permitido o descarregamento para uso pessoal, pelo que o emprego do(s) título(s) descarregado(s) para outro fim, designadamente comercial, carece de autorização do respetivo autor ou editor da obra.

Na medida em que todas as obras da UC Digitalis se encontram protegidas pelo Código do Direito de Autor e Direitos Conexos e demais legislação aplicável, toda a cópia, parcial ou total, deste documento, nos casos em que é legalmente admitida, deverá conter ou fazer-se acompanhar por este aviso.

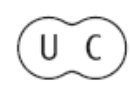




\section{N ○ TASEC O N O MICAS}

$\Delta$

\section{PAUL KRUGMAN'S TRIPLE DOCTORATE}

JORGE BRAGA DE MACEDO

PAUL KRUGMAN JOSÉ SILVA LOPES

ANDRÉ CHAîNEAU

ADÃO CARVALHO

ELSA DE MORAIS SARMENTO/

VANDA DORES /

GUIDA NOGUEIRA

ECONOMISTA MILITANTE

ECONOMICS IN THE CRISIS

COMMENT

LA MONNAIE ET SẸS SINGULARITÉS

FINANCIAMENTO PÚBLICO Ȧ I\&D EMPRESARIAL EM PORTUGAL

A COMPETITIVIDADE E A DIVERSIFICAC,ÃO DA FILEIRA FLORESTAL PORTUGUESA

$\Leftrightarrow$

$\Leftrightarrow$

$(-)$

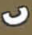

(2)

$\theta$

a

$\theta$ 37

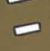
क

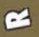
iv 


\section{Financiamento Público à I\&D Empresarial em Portugal*}

\section{Adão Carvalho Departamento de Economia; CEFAGE-UE, Universidade de Évora}

\section{abstract}

The will to foster a knowledge-based economy has led many countries, including Portugal, to a greater compromise with public policies to stimulate business R\&D. The general trend to design policies in accordance with the political goals set for business R\&D intensity is the visible expression of the mission that governments have accepted to that end. Recent changes in the public policies to foster business R\&D raise or revive issues at different levels that deserve a critical analysis that is not taking place, namely in Portugal. This paper makes a contribution to the discussion about the role and the limits of the public policies to stimulate business R\&D by estimating the weight of the public support of business R\&D in Portugal and analyzing its evolution from 1997 to 2010 . There has been a sustained growth of the public funding of business R\&D as percentage of GDP over the period that reached $0.13 \%$ in 2009 ; as a percentage of BERD, the evolution has been irregular but the level of support has been quite high, sometimes over $18 \%$.

\section{resumo}

A vontade de construir uma economia baseada no conhecimento e na inovação tem justificado o compromisso de muitos países, incluindo Portugal, com políticas de estímulo ao investimento empresarial em I\&D. A tendência geral para a definição das políticas em função de objetivos políticos de intensidade de I\&D é a expressão mais visível do sentido de missão que os governos têm assumido neste âmbito. As alterações recentes nas políticas públicas de estímulo ao investimento empresarial em I\&D levantam ou reavivam questões a diversos níveis que merecem uma análise crítica que não está a acontecer, nomeadamente em Portugal. Este artigo contribui para a discussão sobre o papel e os limites das políticas públicas no estímulo à I\&D empresarial ao estimar o peso do investimento público na I\&D empresarial em Portugal e analisar a sua evolução entre 1997 e 2010. Registou-se um crescimento sustentado do financiamento público à I\&D empresarial em percentagem do PIB ao longo do período que atingiu 0,13\% em 2009; em percentagem do BERD, a evolução foi intermitente mas os valores foram elevados, por vezes superiores a $18 \%$.

Classificação JEL: H25, O32, 038

\footnotetext{
* Uma versão preliminar deste artigo foi apresentada no «15. ${ }^{\circ}$ Workshop APDR» sobre Políticas Públicas, que teve lugar na Universidade de Évora, Portugal, em 24-10-2012. A versão final deste texto beneficiou dos comentários e sugestões de um referee anónimo, ao qual gostaria de expressar o meu agradecimento. Quaisquer erros ou inconsistências remanescentes são, contudo, da exclusiva responsabilidade do autor.
} 
O apoio público ao investimento em investigação e desenvolvimento (I\&D) empresarial é uma prática generalizada nos países da OCDE que se tem consolidado ao longo de várias décadas, mas que nem por isso está isento de controvérsia. O objetivo da União Europeia (UE) em tornar-se a economia baseada no conhecimento mais dinâmica do mundo em 2010 assinalou uma mudança estratégica nas políticas públicas de I\&D e o reforço do papel que os países da UE atribuíram a si mesmos no estímulo à I\&D empresarial, cujas repercussões extravasaram muito a própria UE. A política baseada em objetivos e o crescente aumento da generosidade dos incentivos públicos à I\&D empresarial são dois vértices dessa mudança de paradigma. Outro é a alteração na racionalidade do financiamento público à I\&D empresarial que cada vez menos se baseia nas tradicionais falhas de mercado (investimento privado em I\&D abaixo do ótimo social), e mais na promoção da inovação e do crescimento económico (I\&D enquanto base da inovação e do crescimento económico), e, mais recentemente, na concorrência entre países (e zonas económicas) por investimento em I\&D e investigadores (atração de novos investimentos internacionais de I\&D e preservação de recursos de I\&D já existentes no país) (Carvalho, 2011, 2012).

O investimento em I\&D é um indicador fundamental da capacidade para construir uma economia baseada no conhecimento e na inovação, o que justifica o comprometimento crescente de muitos países, incluindo a generalidade dos Estados Membros da UE, com políticas públicas de estímulo ao investimento empresarial em I\&D. Um investimento regular e elevado em I\&D pelo setor empresarial, particularmente em atividades de média-alta e alta tecnologia, é tido como fundamental para gerar e manter um fluxo regular de inovação na atividade económica capaz de sustentar a competitividade e o crescimento económico de uma economia baseada no conhecimento ${ }^{1}$. Esse comprometimento é evidente nas políticas públicas de um crescente número de países que definem objetivos concretos para a intensidade de $\mid \& D$ empresarial ${ }^{2} \mathrm{e}$ consideram esses objetivos como referências fundamentais na construção dos seus planos de desenvolvimento da ciência, tecnologia e inovação (C,T\&l) de médio e longo prazos. É um fenómeno à escala mundial que não se restringe aos países tecnologicamente mais avançados e/ou que mais investem em I\&D3. Esse empenhamento tem sido igualmente evidente em Portugal ao longo dos últimos anos e nomeadamente a partir de 2005, com a definição de objetivos de I\&D e a implementação de políticas públicas de estímulo à I\&D empresarial, tendose registado uma evolução muito favorável do indicador intensidade de I\&D empresarial nos anos mais recentes (GPEARI, 2011).

A tendência crescente para a definição das políticas públicas de C,T\&I em função de objetivos de intensidade de I\&D são a expressão visível da missão que os governos têm vindo a assumir para aumentarem o investimento empresarial em I\&D. Isso levanta ou reaviva questões de políticas públicas a diversos níveis que vão desde o papel de timoneiro assumido pelos estados (e pela UE) na definição de objetivos quantificados para o investimento privado em I\&D, passando pelos limites do financiamento público à I\&D empresarial e as questões de

\footnotetext{
${ }^{1}$ Isso não é, obviamente, uma condição suficiente, sendo igualmente importante que outros agentes do sistema de inovação tenham um desempenho compatível, por exemplo, ao nível do investimento das universidades em I\&D, da qualidade da formação dos recursos humanos ou das relações de cooperação entre empresas e as universidades e instituições de investigação.

${ }^{2} \mathrm{O}$ indicador intensidade de I\&D mede a relação entre o investimento em I\&D e o PIB, em percentagem. A intensidade de I\&D empresarial é a percentagem do investimento que as empresas fazem em I\&D em relação ao PIB.

${ }^{3}$ O caso mais óbvio é o da UE que em 2010 renovou as metas da intensidade de I\&D empresarial (2\% do PIB) para 2020 (European Commission, 2010). Em 2011, quase todos os países membros da UE definiram objetivos concretos para este indicador no âmbito da estratégia europeia «Europa 2020" (ver documentos estratégicos dos países da UE em http://ec.europa.eu/europe2020/index en.htm).
} 
concorrência que daí podem advir, passando pela eficiência (ou ineficiência) no uso de recursos públicos decorrente da vontade dos governos em estimularem as empresas a investir em I\&D para cumprirem objetivos políticos, até à eficácia das políticas públicas que se centram cada vez mais na quantidade de I\&D realizada e menos nos fundamentos económicos ou interesse estratégico para o Estado (setores, tecnologias ou áreas científicas) como estratégia para desenvolver uma economia baseada na inovação e no conhecimento. Estas alterações recentes nas políticas públicas de I\&D e na missão que o Estado entende que deve ter merecem uma reflexão crítica que não está a acontecer, nomeadamente em Portugal.

Este artigo pretende contribuir para a discussão sobre o apoio público à I\&D empresarial, os limites desse apoio e o papel das políticas públicas no contexto das economias baseadas no conhecimento. Partindo da informação oficial disponível e de informação estatística da OCDE, o trabalho tem como objetivo principal estimar o peso global do investimento público (financiamento direto mais incentivos fiscais) na I\&D empresarial em Portugal e analisar a sua evolução de 1997, ano da introdução do Sistema de Incentivos Fiscais à I\&D Empresarial (SIFIDE) em Portugal, a 2010, último ano em que existe informação disponível. Em Portugal não tem havido grande discussão sobre os limites do financiamento público à I\&D empresarial mesmo porque não se vislumbra nos diversos setores da sociedade portuguesa (empresarial, académico, político) qualquer reação relevante contra a necessidade de aumentar o investimento empresarial em I\&D em Portugal e aproximá-lo da média da UE. Nem quanto ao crescente protagonismo assumido pelo Estado a partir de meados da década passada. Por outro lado, tal discussão exige informação adequada e atualizada sobre o financiamento público da I\&D empresarial que não estará publicamente disponível. A OCDE nem sequer publica regularmente um indicador global dos financiamentos diretos e dos benefícios fiscais de que as empresas beneficiam que permita conhecer o peso global do financiamento público na I\&D empresarial de cada país e a sua comparação internacional. Por outro lado, há uma tendência crescente para o aumento do peso relativo dos incentivos fiscais no conjunto de apoios públicos à I\&D empresarial em detrimento do financiamento direto (Carvalho, 2012; OECD, 2008b), que pode dificultar ainda mais o acesso à informação 4 .

Em termos de estrutura, o artigo aborda em primeiro lugar o contexto favorável do estímulo público à I\&D em geral e I\&D empresarial em particular, depois analisa os tipos de instrumentos mais relevantes e compara o financiamento público à I\&D empresarial nos países da OCDE e, de seguida, faz uma análise cronológica do financiamento público à I\&D empresarial em Portugal. Algumas conclusões e implicações fecham o artigo.

\section{Estímulo à I\&D Empresarial}

Não sendo recentes, as políticas públicas de estímulo ao investimento privado em I\&D ganharam outra dimensão no contexto das economias baseadas no conhecimento. Há uma pressão política forte ao nível da União Europeia e de cada Estado Membro para estimular o investimento em atividades de I\&D, em particular a I\&D empresarial ${ }^{5}$. Essa pressão intensificouse bastante no quadro da «Estratégia de Lisboa» em 2000 e da cimeira de Barcelona em 2002, quando se estabeleceu o objetivo de investir 3\% do PIB em I\&D para a média da UE em 2010, devendo a I\&D empresarial representar dois terços daquele valor (European Commission, 2003). Apesar dos resultados alcançados terem sido modestos, em 2010 a UE reafirmou aqueles objetivos no âmbito da estratégia «Europa 2020» (European Commission, 2010).

\footnotetext{
${ }^{4}$ Para além de não haver um orçamento a priori para os incentivos fiscais, é normal as empresas poderem reclamar os benefícios durante um período de tempo alargado, que em Portugal é de 6 anos após a realização do investimento em I\&D.

5 «O montante dos auxílios estatais a favor das despesas de investigação, desenvolvimento e inovação aumentou, tendo passado de 6,2 milhões de euros em 2005 para 10,9 milhões de euros em 2010 (+75\%)» (Comissão Europeia, 2012a).
} 
No atual contexto competitivo, boa parte da capacidade competitiva das empresas presente e futura, e por extensão dos países onde têm atividades económicas, deriva da sua maior ou menor capacidade para produzir, endogeneizar, transferir, usar e proteger o conhecimento científico e tecnológico. O conhecimento tornou-se o fator competitivo por excelência, que se destaca de outros fatores produtivos outrora mais relevantes por ser muito mais difícil de replicar dada a sua componente tácita, por estar muito relacionado com o contexto onde é produzido e utilizado, e pelo facto da matriz do conhecimento de muitas indústrias recentes ser de origem científica. Desde a criação dos primeiros departamentos de I\&D nas empresas nos finais do séc. XIX (Freeman e Soete, 2007) que investir em I\&D se tornou importante por questões de competitividade e inovação empresarial, sendo fundamental nas novas indústrias intensivas em conhecimento. Para prosperar numa economia baseada no conhecimento e na inovação, países como Portugal, com uma percentagem reduzida de empresas e produtos de média-alta e alta tecnologia e investimento empresarial em I\&D historicamente baixo ${ }^{6}$, o aumento do investimento privado em I\&D é vital mas o percurso é mais difícil em face do ponto de partida mais atrasado.

Do ponto de vista das políticas de $C, T \& I$, ao longo da última década emergiram dois factos que merecem destaque na cruzada dos governos para estimularem o investimento em I\&D. Por um lado, consolidou-se a era das políticas de I\&D orientadas por objetivos (Carvalho 2011, 2012), sendo crescente o número de países que define as suas políticas públicas de ciência e tecnologia em função de objetivos quantificados para os indicadores de intensidade de I\&D global (GERD em percentagem do PIB) e intensidade de I\&D empresarial (BERD em percentagem do $\mathrm{PIB})^{7}$. O fenómeno tem vindo a consolidar-se no seio dos países da UE e da OCDE e a alastrar-se a outros países emergentes como a China, o Brasil, a Índia, a Rússia e a África do Sul (OECD, 2010b). A Espanha, por exemplo, tem vindo a definir consistentemente objetivos quantificados de I\&D nos 5 programas de estímulo à ciência, tecnologia e inovação elaborados na última década (Carvalho, 2012). Portugal seguiu a tendência internacional e também estabeleceu objetivos concretos de I\&D no âmbito do Plano Tecnológico (Governo de Portugal, 2005). Neste plano estabeleceu-se a meta ambiciosa de triplicar o investimento em I\&D empresarial até 2010, para atingir $0,8 \%$ do PIB, comprometendo-se o governo de então a criar «as condições de estímulo necessárias» para atingir tal objetivo (Governo de Portugal, 2005). Para atingir os objetivos que estabelecem para o indicador intensidade de I\&D, os governos têm de criar estímulos suficientes para convencer as empresas que já investem em I\&D a aumentar esse investimento, e outras empresas que não investem em I\&D (como é o caso da generalidade das PME) a fazê-lo, sem perder de vista a variação do PIB que influencia diretamente o indicador intensidade de $I \& D^{8}$.

É neste contexto global de políticas públicas orientadas para objetivos de I\&D, em particular objetivos de I\&D empresarial cuja concretização só indiretamente está dependente das políticas públicas, que ocorre o segundo facto relevante - o aumento dos incentivos à I\&D empresarial e a crescente generosidade desses incentivos até ao ponto de gerar concorrência direta entre países (OECD, 2008b; Carvalho, 2011, 2012). Um número crescente de países tem vindo a implementar sistemas de incentivos fiscais (mesmo países tradicionalmente avessos a este tipo de incentivos), o peso relativo dos incentivos fiscais tem vindo a crescer (e o peso dos incentivos

\footnotetext{
${ }^{6} \mathrm{O}$ investimento do setor empresarial em I\&D (0,69\% do PIB) representou em 2011 cerca de $46 \%$ do investimento total em I\&D (1,50\% do PIB) realizado em Portugal e cerca de $55 \%$ do investimento do setor empresarial da UE (1,26\% do PIB), valor ainda muito distante dos dois terços desejados pela UE (Eurostat, dados extraídos em 21-02-2013).

${ }^{7}$ De acordo com o Manual de Frascati (OECD, 2002), o investimento total em I\&D de um país (cuja sigla é GERD) é subdividido em quatro setores de execução: empresas (BERD), ensino superior (HERD), estado (GOVERD) e instituições privadas sem fins lucrativos (PNP).

${ }^{8} \mathrm{Se}$ o PIB crescer no período em causa obriga a que o investimento das empresas em I\&D seja mais elevado e exige, porventura, mais incentivos públicos para que tal aconteça. Se o PIB estagnar ou diminuir, as empresas tendem a retrair os investimentos em I\&D e o Estado poderá ter que aumentar os incentivos para atingir os objetivos definidos.
} 
financeiros a diminuir) no total dos incentivos públicos à I\&D empresarial, e os esquemas de incentivos para captar I\&D de empresas internacionais e/ou manter os recursos de I\&D existentes no país, são cada vez mais desenhados e alterados em função dos esquemas de incentivos oferecidos por países concorrentes (potenciais destinatários desses investimentos). Portugal é um exemplo claro desta tendência. Em Portugal, o sistema de incentivos à I\&D empresarial (SIFIDE) sofreu diversas alterações desde a sua introdução em 1997 (e reintrodução em 2006) para aumentar a atratividade face a outros sistemas de incentivos concorrentes (nomeadamente o espanhol), que o tornaram um dos sistemas de incentivos mais generosos da OCDE. Isso é visível na Figura 1, que ainda não considera as alterações no SIFIDE verificadas em 2009, e que compara o valor do subsídio fiscal em euros atribuído às empresas por cada euro gasto em I\&D nos anos de 1999 e 2008.

Figura 1 - Subsídio Fiscal à I\&D em Países Selecionados, 1999 e 2008 ( $€$ de subsídio por $€$ gasto em I\&D)

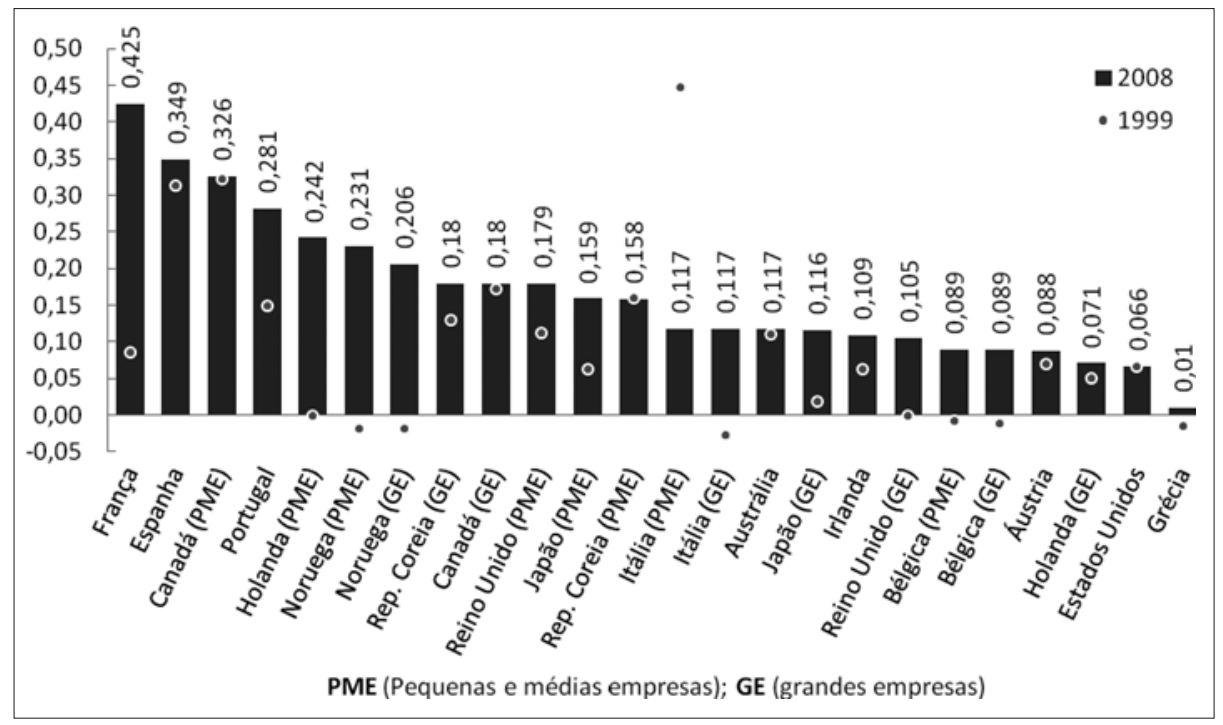

Fonte: OECD (2010b, com base na Figure 2.2, p. 104).

É percetível a tendência para o aumento do financiamento indireto à I\&D empresarial no período considerado dado que dos países considerados apenas a Itália diminuiu o benefício fiscal às PME. Muitos países, entre os quais a França, Portugal, a Holanda a Noruega e o Japão, aumentaram bastante o benefício fiscal à I\&D empresarial. De acordo com a Figura 1, em 2008, por cada euro investido em I\&D pelas empresas em Portugal, estas tinham a possibilidade de beneficiar de uma redução de 0,281€ na carga fiscal. Em 1999, esse benefício fiscal era cerca de $0,15 €$. Em França por cada euro de investimento em I\&D em 2008 estimou-se um benefício fiscal de $0,425 €$, que compara com o benefício fiscal de cerca de $0,085 €$ registado em 1999. Lido de outra maneira, em 2008 as empresas portuguesas dispunham de um subsídio fiscal correspondente a cerca de $28 \%$ do investimento realizado em I\&D .

${ }^{9}$ Desde que tivessem lucro porque o subsídio fiscal é atribuído na forma de redução do IRC a pagar. Em Portugal o benefício pode ser reclamado até ao sexto ano após a realização do investimento. 
Há múltiplas formas de apoio público à I\&D empresarial e todos os países da UE e da OCDE têm políticas públicas para estimular as empresas a investirem em I\&D, embora com diferenças relevantes de país para país quanto ao nível de apoio e mix de instrumentos que materializam esse apoio. Podemos destacar dois grandes tipos de instrumentos públicos de apoio à I\&D empresarial (Van Pottelsberghe et al., 2003): o financiamento direto de projetos de I\&D através de subsídios (a fundo perdido ou reembolsáveis), bolsas, empréstimos e outras subvenções financeiras; os incentivos fiscais (financiamento indireto), que reduzem o montante do imposto a pagar pelas empresas, tais como créditos fiscais, amortizações aceleradas, taxas de amortização superiores a $100 \%$ e a majoração de determinado tipo de custos para efeitos contabilísticos. O financiamento direto implica a cativação de verbas previamente orçamentadas, sendo o montante do apoio público determinado antes da realização das atividades de I\&D, normalmente em função do resultado de concursos públicos aos quais os interessados se candidatam (o QREN ${ }^{10}$ é um exemplo atual em Portugal). Contrariamente, os incentivos fiscais são determinados após a realização das atividades de I\&D e o apoio é concedido por via da redução dos impostos (IRC) que a empresa teria a pagar. Há ainda muitos apoios públicos indiretos à I\&D empresarial por via das políticas públicas destinadas a melhorar ou reforçar o Sistema Científico e Tecnológico Nacional, nomeadamente através do financiamento público à I\&D nas universidades e instituições de investigação públicas, o financiamento público de equipamentos e estruturas de investigação, o reforço das medidas de proteção da propriedade intelectual ou o financiamento do sistema público de ensino.

O financiamento direto e os incentivos fiscais são instrumentos com características diferentes e são apenas parcialmente substituíveis entre si. Tradicionalmente, as políticas públicas privilegiavam o financiamento direto à $1 \& D$ empresarial mas a tendência recente aponta para o crescente aumento do número de países com sistemas de incentivos fiscais à $I \& D$, havendo mesmo uma gradual substituição dos financiamentos diretos pelos incentivos fiscais (OECD, 2008b), que o caso de Portugal ilustra bem como veremos adiante. Esta alteração está relacionada, por um lado, com a crescente escassez de meios financeiros públicos disponíveis que se tem vindo a manifestar há já vários anos na Europa e que certamente se agravou no contexto da crise económica e financeira em curso, e, por outro, porque os incentivos fiscais são instrumentos cuja flexibilidade, universalidade e condições de acesso os torna mais ajustados à mudança recente nas políticas públicas de estímulo à I\&D empresarial e à realização dos objetivos políticos nesta matéria. Em Portugal, historicamente têm predominado as medidas de financiamento direto a fundo perdido (com algumas exceções) e as deduções fiscais em sede de IRC. São benefícios acumuláveis: os projetos de investimento em I\&D podem ser objeto de benefícios fiscais na parte não financiada por financiamento direto.

Em termos gerais, o financiamento direto é mais apropriado para canalizar recursos de I\&D para setores empresariais, tecnologias ou áreas científicas específicas, para corrigir alguma escassez de investimento, falha de mercado ou reforçar alguma capacidade já existente considerada estratégica para o interesse público. É, portanto, mais adequado para atingir objetivos estratégicos em que o Estado quer ter controlo sobre o âmbito e o processo. Os recursos públicos são normalmente atribuídos por concurso público, através de um processo competitivo que garante ao Estado maior controlo orçamental do montante de apoios a atribuir e maior controlo dos objetivos de política pública (setores, tecnologias ou áreas científicas) que visa atingir. Os incentivos fiscais, por seu lado, não exigem um orçamento inicial porque o apoio público é concedido sob a forma de redução do imposto a pagar pelas empresas (depois de realizadas as atividades de I\&D), mas o Estado tem mais dificuldade em estimar e controlar o montante dos incentivos a atribuir, o âmbito dos projetos que apoia e os beneficiários dos incentivos. São menos discricionários em termos do tipo de investigação a realizar (em termos

10 Quadro de Referência Estratégico Nacional (QREN), sistema de incentivos em Portugal para 2007-2013. 
de setores, tecnologias ou áreas científicas) pois as empresas ficam com independência para decidir em que projetos investir e quando investir. São também menos restritivos no tipo de empresas que podem aceder aos incentivos, e encorajam mesmo as PME a investir em I\&D, para além de evitarem ao Estado a tarefa e o risco associados com a escolha dos «melhores projetos de I\&D» em concursos públicos ${ }^{11}$. Isto faz com que os incentivos fiscais à I\&D empresarial sejam potencialmente indutores de maior ineficiência no uso de recursos públicos.

Figura 2 - Financiamento Público à I8D Empresarial em Percentagem do PIB nos Países da OCDE, 2008

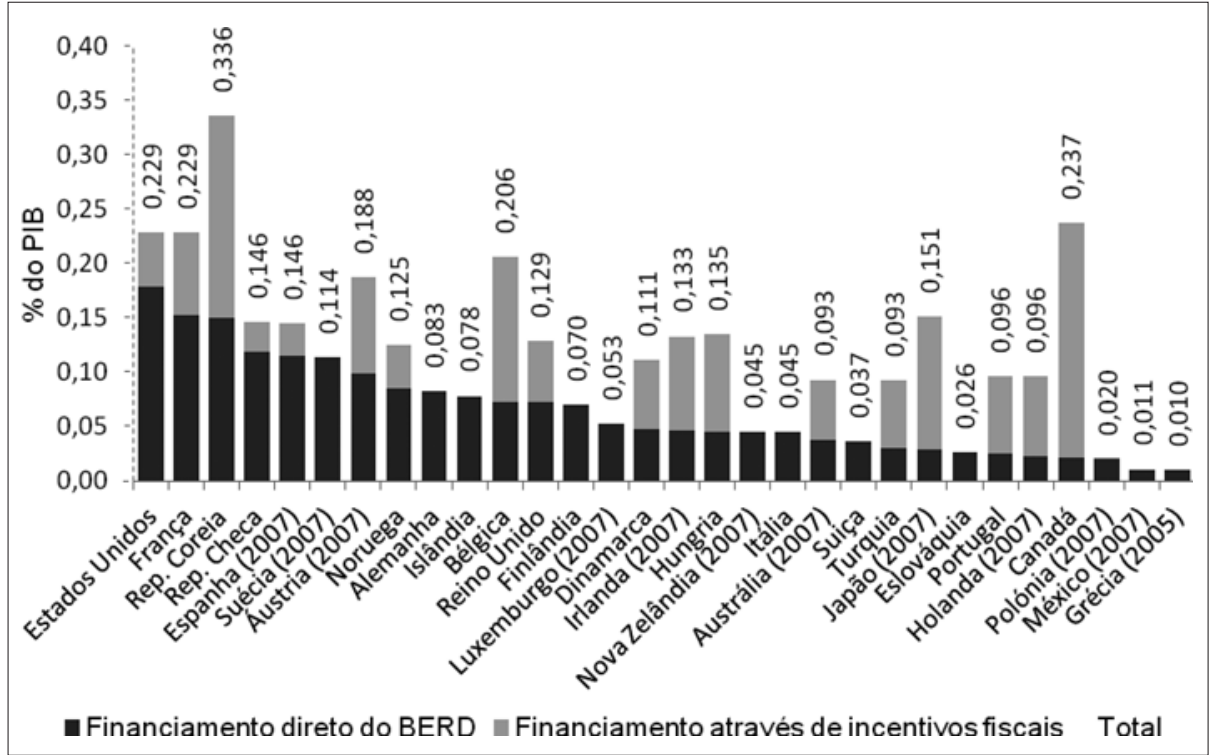

Fonte: OECD (2010b, com base na Figure 2.1, p. 103).

A Figura 2 faz uma comparação do financiamento público à I\&D empresarial como percentagem do PIB nos países da OCDE, para o ano de $2008^{12}$. Há uma diferença grande entre os países da OCDE no nível global de apoio público à I\&D empresarial, mas em geral os países que mais investem em I\&D tendem a ter um nível de apoio público mais elevado. Há também diferenças relevantes na percentagem relativa de cada tipo de apoio em cada país. $O$ financiamento direto do BERD é uma prática generalizada ao contrário dos incentivos fiscais que existem apenas em cerca de dois terços dos países da OCDE, embora haja uma clara tendência para aumentar o número de países com sistemas de incentivos fiscais de apoio à I\&D empresarial, como foi referido anteriormente. É visível igualmente que Portugal (0,096\% do

11 Ver Carvalho (2012) para mais informação.

${ }^{12}$ Como veremos mais adiante no Quadro 1, os dados dos incentivos fiscais relativos a Portugal já estão desatualizados. Em OECD (2011b) há uma versão atualizada da Figura 2 para o ano de 2009, que na verdade apresenta a mesma informação para mais de metade dos países da Figura 2, incluindo a Espanha, a Áustria, a Nova Zelândia e o México cuja informação se refere a 2007. Isso alarga o período de referência e torna os dados menos comparáveis. 
PIB) está longe de ser dos países que mais financia a I\&D empresarial em percentagem do PIB mas está à frente de países como a Alemanha, a Austrália ou a Finlândia. Vários países ultrapassam os $0,2 \%$ do PIB e a República da Coreia atinge mesmo 0,336\% do PIB. Tal como em Portugal, de acordo com a Figura 2, em vários outros países os incentivos fiscais são proporcionalmente maiores do que o financiamento direto no total do financiamento público à I\&D empresarial: República da Coreia (55\%), Austrália (59\%), Bélgica (65\%), Irlanda (65\%), Holanda (77\%), Japão (80\%). No Canadá os incentivos fiscais representavam mais de $90 \%$ do total do financiamento público em 2008.

\section{Financiamento Público da I\&D Empresarial em Portugal}

A informação disponível sobre o financiamento público à I\&D empresarial em Portugal é escassa, dispersa e incompleta. Não existe informação oficial sobre o montante global do financiamento público ao longo dos anos (financiamento direto e incentivos fiscais) e a informação sobre os benefícios fiscais à I\&D empresarial foi recolhida de diversas fontes, desde relatórios oficiais (Comissão Certificadora, 2010), relatórios da OCDE (2008b,2010a,2010b), apresentação em eventos (Lajas, 2012), até publicações ad hoc do Ministério das Finanças (2012). Mesmo assim, não foi possível obter informação suficiente sobre os benefícios fiscais para o ano de 2004, nem conhecer o valor do montante dos benefícios fiscais relacionados com a «Reserva Fiscal para Investimento» que substituiu o SIFIDE em 2004 e 2005. Isto representa um obstáculo importante a uma análise detalhada do fenómeno e torna mais difícil a discussão sobre os limites do financiamento público à I\&D empresarial, mas torna igualmente mais pertinente o objetivo deste artigo. Vamos tentar compreender o fenómeno em Portugal através do peso relativo do financiamento público no $\mathrm{PIB}$, como é feito no ponto anterior, mas vamos igualmente estimar o peso do financiamento público no BERD (investimento empresarial em I\&D).

O Quadro 1 dá-nos a evolução do financiamento público à I\&D empresarial em Portugal em percentagem do PIB e do BERD, no período de 1997 a 2010 (exceto 2004) ${ }^{13}$. Estas datas balizam o início do sistema de incentivos SIFIDE e o último ano em que há informação disponível para estimar o valor global do financiamento público ${ }^{14}$. Na determinação do financiamento público foram consideradas duas variáveis: os financiamentos diretos à I\&D empresarial em percentagem do BERD, obtidos a partir da série estatística da OCDE, e os incentivos fiscais à I\&D empresarial, obtidos a partir do crédito fiscal aprovado do programa SIFIDE ${ }^{15}$. A OCDE publicou estimativas do financiamento público global à I\&D empresarial em percentagem do PIB para um conjunto selecionado de países, para os anos de 2005, 2007 e 2008 (OECD 2008b, 2010a, 2010b) (ver Figura 2 para 2008) e, na ausência de melhor informação, foram utilizados os dados da OCDE para o ano de $2005^{16}$. A OCDE não apresenta indicadores do financiamento público da I\&D empresarial em percentagem do BERD e também não é conhecida qualquer publicação oficial que determine esse indicador para Portugal, mas esse indicador permite

13 O SIFIDE foi substituído pela Reserva Fiscal para Investimento em 2004 e 2005 e reintroduzido em 2006.

14 O Ministério das Finanças publicou em 28-09-2012 um documento com o valor dos incentivos fiscais no âmbito do SIFIDE relativos a 2011, cujo valor é de $80791812,3 €$, com a seguinte nota: «Apenas foram incluídos na Lista os sujeitos passivos de IRC que na sua declaração de rendimentos relativa ao período de tributação de 2011 tenham invocado benefícios fiscais de valor igual ou superior a $€$ 1000,00" (Ministério das Finanças, 2012). Este valor não vai ser utilizado na análise do Quadro 1 por ser truncado e não ser claro se se trata de incentivos aprovados ou utilizados pelas empresas.

${ }_{15}$ Assume-se que os créditos fiscais compreendem a totalidade dos incentivos fiscais e que todos os créditos fiscais aprovados foram efetivamente utilizados pelas empresas. Dado que desde 2006 as empresas têm 6 anos para reclamar créditos de imposto, é provável que os valores dos créditos aprovados desde 2006 ainda venham a ser atualizados porque há candidaturas em análise (Lajas, 2012). Por outro lado, falta informação sobre os benefícios no âmbito da «Reserva Fiscal para Investimento». Isso indica-nos que as estimativas encontradas estarão feitas por defeito.

${ }^{16}$ Apesar das limitações inerentes à utilização de fontes de informação diferentes. Contudo, sem essa informação não era possível fazer qualquer estimativa para o ano de 2005. 


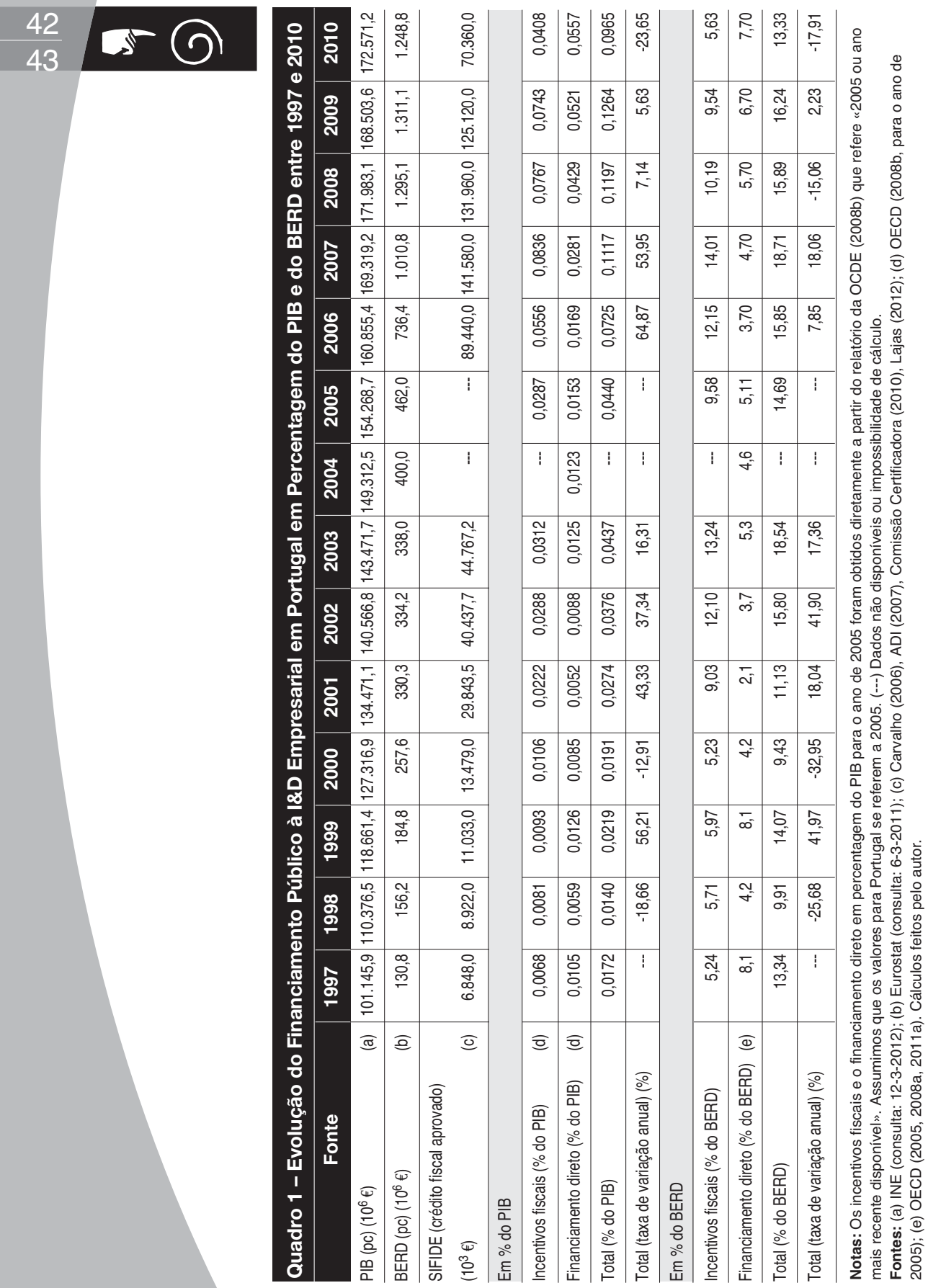


Financiamento Público à I\&D Empresarial em

Adão Carvalho Portugal

avaliar mais objetivamente a importância do financiamento público na I\&D empresarial. As Figuras 3 e 4 mostram a evolução do financiamento público à I\&D empresarial em Portugal no período entre 1997 e 2010, em percentagem do PIB e do BERD, respetivamente.

\section{Figura 3 - Financiamento Público à I\&D Empresarial em Percentagem do PIB, 1997-2010}

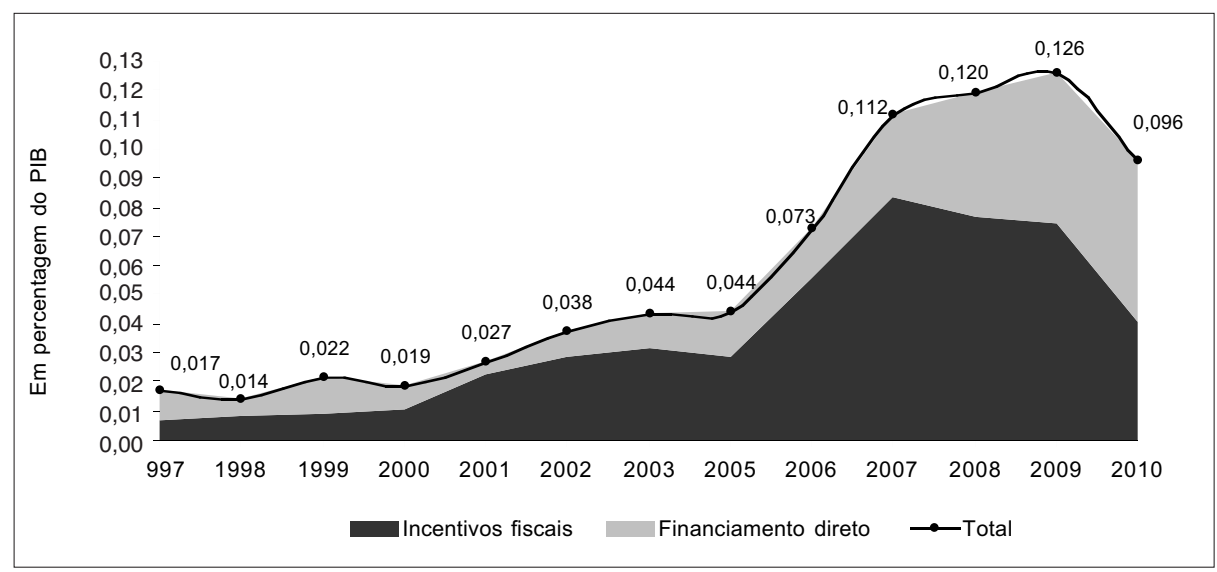

Fonte: Quadro 1.

Nota: $\mathrm{O}$ ano de 2004 foi excluído por falta de dados.

\section{Figura 4 - Financiamento Público à I\&D Empresarial em Percentagem do BERD, 1997-2010}

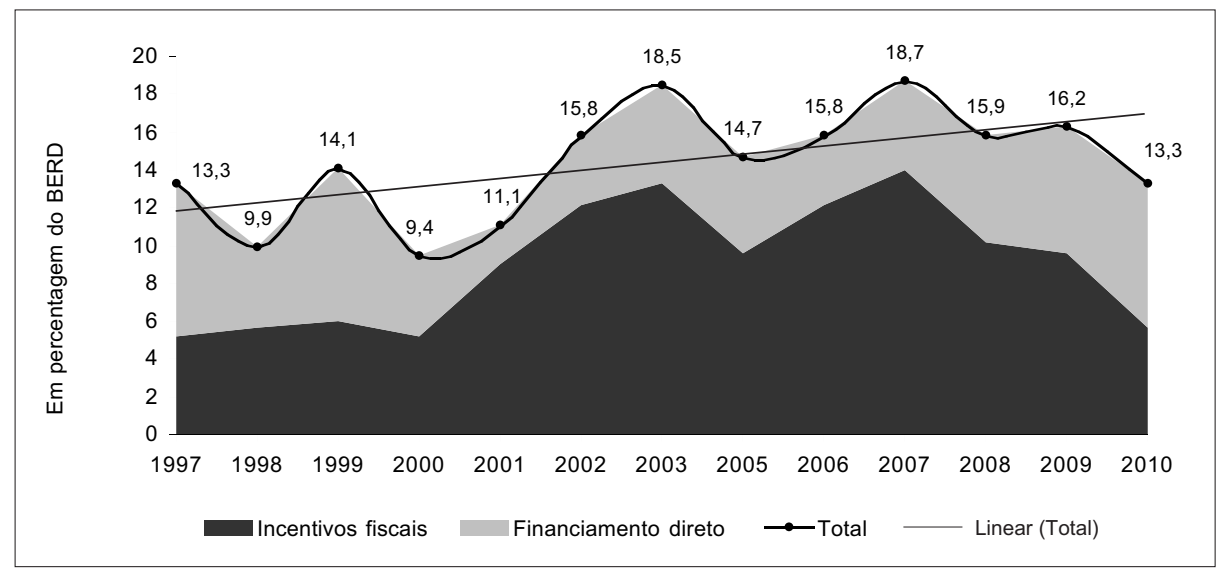

Fonte: Quadro 1.

Nota: $\mathrm{O}$ ano de 2004 foi excluído por falta de dados. 
Do Quadro 1 e da Figura 3 observa-se que houve uma evolução positiva quer dos incentivos fiscais, quer do financiamento direto em percentagem do PIB ao longo do período em análise, mas a taxa de crescimento dos incentivos fiscais foi muito superior à taxa de crescimento do financiamento direto, pelo menos até 2007. O peso do financiamento público total aumentou mais de 6,4 vezes entre 1997 e 2009, passando de menos de 0,02\% do PIB português em 1997 para cerca de $0,13 \%$ do PIB em 2009. A estagnação verificada entre 2003 e 2005 deve-se certamente à ausência de informação completa sobre os incentivos fiscais para este período, mas é também o resultado da substituição do SIFIDE pela Reserva Fiscal para Investimento que não foi convincente para as empresas. A Figura 2 colocava Portugal a meio da tabela dos países da OCDE em 2008 com um valor próximo dos $0,1 \%$ do PIB. O relatório sobre os auxílios estatais concedidos pelos Estados Membros da UE (Comissão Europeia, 2012b) refere que os «auxílios horizontais de interesse comum» relativos à investigação, desenvolvimento e inovação (I\&D\&I) em 2011 atingiram 10 mil milhões de euros, ou seja, 0,08\% do PIB da UE ${ }^{17}$. Os valores médios da OCDE e da UE são, portanto, bastante inferiores ao de Portugal. A atualização dos dados para Portugal para 2008 e o forte crescimento do financiamento público em percentagem do PIB verificado a partir de 2005 permitiu superar largamente a média da UE e terá reposicionado Portugal mais acima na tabela da OCDE em 2009. Portugal seguiu a tendência dos países da OCDE de aumento do peso relativo dos incentivos fiscais no total dos incentivos públicos, que se deveu em grande medida às múltiplas alterações ocorridas no SIFIDE que desde 2006 o tornaram num dos sistemas de incentivos fiscais à I\&D empresarial mais generosos dos países da OCDE.

O peso dos incentivos fiscais no total de incentivos públicos aumentou de cerca de 39\% em 1997 para $75 \%$ em 2007, ano em que atingiu o seu valor máximo, baixando para $64 \%$, 59\% e $42 \%$ nos anos seguintes. A análise da evolução nos anos mais recentes deve ser feita com cautela porque os valores dos incentivos fiscais são provisórios e é provável que haja ainda alterações significativas a julgar pela informação já disponível ${ }^{18}$. Em termos relativos, o peso dos incentivos fiscais no PIB aumentou mais de 10 vezes entre 1997 e 2009, a que corresponde um aumento superior a 17 vezes em termos do valor do crédito fiscal aprovado. A evolução do financiamento direto em percentagem do PIB foi menos clara do que a dos incentivos fiscais, com períodos de crescimento e outros de decréscimo, mas é evidente uma taxa de crescimento elevada a partir de 2007, que se deve certamente à implementação do sistema de incentivos QREN 2007-2013 que inclui diversos incentivos para atividades de I\&D, mas é igualmente uma consequência prática do forte empenhamento político em aumentar a I\&D empresarial através do alargamento dos incentivos públicos ${ }^{19}$. O financiamento direto cresceu quase $27 \%$ de 2006 para 2007 e mais de 105\% de 2007 para 2008. Dada a complementaridade dos dois tipos de incentivos, este aumento recente do financiamento direto vai originar um aumento do volume de incentivos fiscais nos anos seguintes porque as empresas podem ter acesso aos benefícios fiscais na componente dos projetos de I\&D que não beneficiou de financiamento direto. Conjugado com a provável redução do financiamento direto nos próximos anos, o peso dos incentivos fiscais no total dos financiamentos públicos vai aumentar.

As Figura 3 e 4 mostram claramente dois períodos em que houve um aumento mais significativo do total dos incentivos públicos em percentagem do PIB, com início em 2001 (43,3\%) e 2006 (55\%) respetivamente, que correspondem a dois momentos em que houve alterações

\footnotetext{
${ }^{17}$ Note-se que este valor inclui também o auxílio público à inovação, e não apenas à I\&D das empresas.

${ }^{18}$ Esta expectativa tem a ver, por um lado, com a enorme diferença entre os valores do SIFIDE publicados pela Comissão Certificadora (2010) e os valores atualizados em Lajas (2012) para 2007 e 2008 e, por outro, porque o valor apresentado pelo Ministério das Finanças (2012) para 2011 (80,792 milhões de $€$ ) é muito superior ao valor disponível em Lajas (2012) para 2010 (70,360 milhões de $€$ ). Isso sugere que o valor de 2010 está desatualizado. O problema da informação desatualizada e do uso de várias fontes seria minorado ou mesmo eliminado caso a Comissão Certificadora do SIFIDE publicasse informação relevante com regularidade, o que não tem acontecido.

19 Entre 2005 e 2008, o investimento das empresas portuguesas em I\&D cresceu cerca de $150 \%$, tendo passado de $0,3 \%$ para $0,75 \%$ do PIB (GPEARI, 2011).
} 
substanciais na generosidade do sistema de incentivos SIFIDE que o tornaram muito mais atrativo para as empresas. O primeiro período vai até 2003 e é muito dominado pelo aumento dos incentivos fiscais (SIFIDE); o segundo período de grande crescimento do financiamento público à I\&D empresarial manifesta-se até 2009 , em que prevalece o aumento dos incentivos fiscais até 2007 (o SIFIDE foi reintroduzido em 2006), destacando-se o financiamento direto em 2008 e 2009 (o QREN teve início em 2007 e os diversos subprogramas foram sendo abertos a partir dessa data). Como já foi referido antes, os valores dos incentivos fiscais são provisórios e certamente haverá alterações.

O Quadro 1 e a Figura 4 mostram-nos uma evolução intermitente, pouco definida embora com tendência para crescer, do financiamento público total à I\&D empresarial em percentagem do BERD. Há uma propensão geral para o aumento dos valores máximos e mínimos deste indicador, o que justifica que tenha uma linha de tendência positiva (Figura 4). O financiamento público variou entre o valor mínimo de 9,43\% em 2000 e o valor máximo de 18,71\% em 2007 do investimento realizado pelas empresas em atividades de I\&D. Os valores máximos registados do financiamento público (em \% do BERD) ocorrem em 2003 (18,5\%) e 2007 (18,71\%), dois a três anos depois das alterações significativas ocorridas no sistema de incentivos fiscais em 2001 e 2005 (com efeitos a partir de 2006), respetivamente. Os dados sugerem que as empresas reagem favoravelmente ao aumento dos incentivos públicos e que há um preço elevado a pagar pelo Estado se quiser aumentar significativamente o investimento empresarial em I\&D no curto prazo.

O financiamento público da I\&D empresarial tem sido bastante significativo em percentagem do BERD e mais ainda em termos absolutos se tivermos em consideração o aumento exponencial do investimento empresarial em I\&D que se verificou em Portugal entre 2005 e 2008 (que se reflete bem na evolução da Figura 3 a partir de 2005). Esse é um risco do Estado associado aos incentivos fiscais porque o Estado não tem controlo a priori sobre o montante do benefício a conceder às empresas, podendo este aumentar mesmo em períodos de contração do PIB. Entre 2002 e 2009 (com exceção de 2005) a taxa de financiamento público situou-se acima dos 15,8\% do BERD, que é uma taxa média elevada embora não seja possível fazer uma comparação internacional por inexistência de dados sobre outros países da OCDE. Trata-se de uma taxa média que foi calculada tendo em consideração a totalidade das empresas que realizaram I\&D nos anos em análise. No entanto, dado que o acesso aos incentivos fiscais está reservado às empresas que apresentam lucros e aquelas que se candidatam a esses incentivos ${ }^{20}$, e considerando a importância relativa dos incentivos fiscais no conjunto do financiamento público, há empresas que beneficiaram de apoio público em taxas muito superiores à taxa média obtida ${ }^{21}$.

\section{Conclusão e Implicações}

Há um consenso generalizado na UE, incluindo Portugal, sobre a necessidade de aumentar o investimento em I\&D e I\&D empresarial em particular, pois a I\&D é tida como o pilar fundamental da competitividade das economias baseadas no conhecimento e na inovação. Isso tem originado mudanças substanciais nas políticas de estímulo à I\&D empresarial em face do papel de liderança que muitos governos assumiram nesta matéria, com implicações estratégicas, orçamentais e económicas relevantes. Tem se consolidado a tendência em muitos países, incluindo Portugal, para implementar políticas de C\&T orientadas por objetivos de I\&D (GERD e BERD em \% do PIB). A UE não foi pioneira a definir objetivos de intensidade de I\&D na política de C\&T, mas deu-lhe dimensão global com a estratégia de Lisboa e os objetivos de Barcelona.

${ }^{20} \mathrm{E}$ não se deve menosprezar a quantidade de empresas que desconhecem o sistema de incentivos. Em Espanha, por exemplo, um estudo revelou que $83,9 \%$ das empresas com investimento em I\&D conheciam o sistema de incentivos fiscais, mas destas apenas 48,2\% utilizava esses incentivos (Martínez-Azúa e Ros, 2008).

${ }^{21}$ É uma questão a merecer a atenção dos investigadores, que poderá ser desenvolvida a partir dos dados setoriais apresentados pela Comissão Certificadora (2010) e pela discriminação dos incentivos por empresa disponibilizada pelo Ministério das Finanças (2012) para 2011. 
Dentro da UE, a pressão crescente para o alinhamento das políticas de C\&T levou a que, no âmbito da «Europa 2020", todos os países fossem compelidos a definir metas individuais para a intensidade I\&D. Entretanto, muitos outros países têm seguido políticas de C\&T semelhantes.

A política de I\&D por objetivos contribuiu para a alteração do mix de instrumentos, aumento da generosidade e atratividade dos incentivos públicos de estímulo ao aumento do investimento das empresas em I\&D (incluindo novas empresas, como as PME). A fundamentação do apoio público à I\&D empresarial alterou-se. O desenho e os resultados das políticas estão hoje mais centrados na quantidade de I\&D que induzem do que na justificação económica do apoio, interesse estratégico nacional ou inovação que promovem. São alterações de substância que levantam ou reavivam questões sobre o papel do Estado no estímulo à I\&D empresarial que não têm merecido a reflexão crítica devida dos investigadores, do governo, nem da sociedade. Por exemplo, a questão do limite saudável da intervenção do Estado no financiamento da I\&D privada, que este trabalho traz para a reflexão ao analisar a evolução do peso do investimento público na I\&D empresarial em Portugal de 1997 a 2010.

Neste período, é manifesto que as políticas públicas tiveram como objetivo aumentar o financiamento público à I\&D empresarial e que uma parte substancial do BERD é atualmente suportada por recursos públicos. Paradoxalmente, Portugal integra o grupo de países da OCDE com melhores incentivos à I\&D empresarial, nomeadamente fiscais, mesmo com maiores limitações estruturais em matéria de I\&D e de recursos económicos e financeiros. Em Portugal registou-se um crescimento sustentado do financiamento público à I\&D empresarial, que representava $0,13 \%$ do PIB em 2009 e colocava Portugal acima do meio da tabela dos países da OCDE. Nalguns países da OCDE o financiamento público à I\&D empresarial é mais do dobro do português, noutros é inferior (incluindo a Alemanha, Itália e Finlândia), mas em termos de intensidade de I\&D empresarial Portugal está no último terço da tabela da OCDE. Em Portugal, o financiamento público à I\&D empresarial (em \% do PIB) aumentou 11\% entre 1997 e 2000, $131 \%$ entre 2000 e 2003 e $186 \%$ entre 2005 e 2009.

A evolução do financiamento público à I\&D empresarial em percentagem do BERD entre 1997 e 2010 registou valores elevados e com tendência de crescimento, mas foi intermitente entre períodos de aumento e de diminuição. Registaram-se dois picos neste indicador, em 2003 $(18,5 \%)$ e 2007 (18,71\%), dois a três anos após alterações importantes introduzidas no SIFIDE, e entre 2002 e 2009 (exceto 2005) a taxa de financiamento público situou-se acima dos 15,8\% do BERD. São taxas médias elevadas que escondem o facto de apenas parte das empresas que investem em I\&D beneficiarem dos incentivos fiscais o que, tendo estes o peso mais elevado no total do financiamento público, indica que parte das empresas beneficiou de apoio público em taxas ainda superiores. Há, portanto, questões de concorrência, de legitimidade e de eficácia da intervenção do Estado que importa trazer à discussão. A falta de dados sobre o financiamento público da I\&D empresarial em percentagem do BERD não permitiu comparar Portugal com os restantes países da OCDE. É provável, contudo, que Portugal esteja acima do meio da tabela da OCDE neste indicador porque há vários países com financiamento público à I\&D empresarial superior a Portugal que investem proporcionalmente mais em I\&D empresarial do que a diferença entre Portugal e esses países no indicador do Figura 2.

Seguindo a tendência dos países da OCDE, o peso dos incentivos fiscais no total de incentivos públicos em Portugal aumentou de cerca de 39\% em 1997 para $75 \%$ em 2007, ano em que atingiu o valor máximo. Isto tem várias implicações. A elevada proporção deste tipo de incentivos potencia riscos que seriam minimizados se houvesse maior equilíbrio entre $o$ financiamento direto e os incentivos fiscais. Os incentivos fiscais, pela sua generosidade, universalidade e facilidade de acesso, têm argumentos que convencem as empresas a investirem em I\&D e são o instrumento público mais eficaz para atingir objetivos de intensidade de I\&D. No entanto, o Estado perde o controlo sobre a investigação que financia dada a independência das empresas na escolha dos projetos de I\&D em que investem, sendo provável o financiamento de I\&D privada que seria realizada mesmo na ausência de incentivos públicos. O Estado não necessita de um orçamento prévio, mas também não controla o montante de 
incentivos fiscais a conceder, que podem aumentar mesmo em períodos de contração do PIB. Mantendo-se as regras de acesso aos incentivos fiscais, é provável que estes aumentem nos próximos anos em face do aumento do financiamento direto registado recentemente, mesmo que o país esteja a atravessar um período de recessão e austeridade. Há também uma questão de eficácia a ponderar. Os governos têm apostado no aumento quantitativo do BERD como forma de fomentar a inovação. É certo que o apoio público promoveu o aumento do BERD, mas não é evidente que consequências isso vai ter na quantidade adicional e qualidade da inovação. A Comissão Europeia já reconheceu a insuficiência do indicador intensidade de I\&D empresarial para aferir sobre a inovação induzida (European Commission, 2010), pelo que o apoio público à I\&D deverá centrar-se mais na inovação que origina e menos na quantidade de I\&D que induz. 
ADI (2007) Relatório de Gestão e Contas de 2006, Agência de Inovação.

Carvalho, A. (2006) Investigação e Desenvolvimento Empresarial: Investir no Futuro, in Branco, M.; Carvalho, M.; Rego, M. (eds.), Economia com Compromisso - Ensaios em Memória de José Dias Sena, pp. 199-214. Évora: Universidade de Évora (https://dspace.uevora.pt:8443/rdpc/handle/10174/3031).

Carvalho, A. (2011) Why are tax incentives increasingly used to promote private R\&D?, CEFAGE-UE Working Paper n. ${ }^{\circ}$ 2011/04, Abril, CEFAGE-UE, Universidade de Évora (http://www.cefage.uevora.pt).

Carvalho, A. (2012) ¿Por qué son los incentivos fiscales cada vez más utilizados para estimular la inversión privada en I + D? (Why are tax incentives increasingly used to stimulate private R\&D spending?), Revista Principios. Estudios de Economía Política., n. ${ }^{\circ}$ 21/2012, Julio, pp. 99-116.

Comissão Europeia (2012a), Relatório sobre a Política de Concorrência 2011, Comunicação da Comissão ao Parlamento Europeu, ao Conselho, ao Comité Económico e Social Europeu e ao Comité das Regiões, $\operatorname{COM}(2012) 253$ final.

Comissão Europeia (2012b), Relatório sobre os Auxílios Estatais Concedidos pelos EstadosMembros da UE - Atualização de 2012, Relatório da Comissão, Atualização de 2012 do Painel de Avaliação dos Auxílios Estatais, COM(2012) 778 final.

Comissão Certificadora (2010) Sistema de Incentivos Fiscais à I\&D Empresarial: 2006-2008, Comissão Certificadora para os Incentivos Fiscais à I\&D Empresarial (FCT, GPEARI, ADI).

European Commission (2003) Investing in Research: An Action Plan for Europe, Communication from the Commission, $\operatorname{COM}(2003) 226$ final/2.

European Commission (2010) Europe 2020 - A Strategy For Smart, Sustainable and Inclusive Growth, Communication From The Commission, COM (2010) 2020 final.

Freeman, C.; Soete, L. (1997) The economics of Industrial Innovation, $3^{\text {rd }}$ ed., London: Pinter.

Governo de Portugal (2005) Plano Tecnológico: Uma estratégia de crescimento com base no Conhecimento, Tecnologia e Inovação, Documento de apresentação, aprovado em Conselho de Ministros em 24/11/2005.

GPEARI (2011) IPCTN10: Resultados Provisórios, Gabinete de Planeamento, Estratégia, Avaliação e Relações Internacionais, Novembro 2011, Lisboa.

(http://www.gpeari.mctes.pt/index.php?idc=47\&idi=581172)

Lajas, C. (2012) Apresentação ADI, seminário «Inovar, Empreender e Financiamento de Projectos" promovido pela Câmara de Comércio Luso-Belga-Luxemburguesa, 11-10-2012 (http://www.cclbl.com/2012/eventos/2012-10-11 seminario/carloslajas.pdf).

Martínez-Azúa; Corchuelo, M. B.; Ros, E. M. (2008) Aplicación de los incentivos fiscales a la inversión I+D en las empresas españolas, Revista de Economía Pública, 187-(4/2008), pp. 9-39.

Ministério das Finanças (2012) Benefícios fiscais relativos ao período de tributação de 2011: Despesa Fiscal Agregada Por Beneficio, Documento Excel disponibilizado on-line em 28-092012 (http://info.portaldasfinancas.gov.pt/pt/dgci/divulgacao/estatisticas/Estatisticas++contribuintes+com+benef\%C3\%ADcios+fiscais.htm).

OECD (2002) Frascati Manual - Proposed standard practice for surveys on research and experimental development, 6th Edition, OECD Publishing.

OECD (2005) Main Science and Technology Indicators, Vol. 2005/1, OECD Publishing. OECD (2008a) Main Science and Technology Indicators, Vol. 2008/1, OECD Publishing. 
Financiamento Público à I\&D Empresarial em

Adão Carvalho Portugal

OECD (2008b) OECD Science, Technology and Industry Outlook 2008, OECD Publishing.

OECD (2010a) Measuring Innovation - A New Perspective, OECD Publishing.

OECD (2010b) OECD Science, Technology and Industry Outlook 2010, OECD Publishing.

OECD (2011a) Main Science and Technology Indicators, Vol. 2011/1, OECD Publishing.

OECD (2011b), OECD Science, Technology and Industry Scoreboard 2011, OECD Publishing.

Van Pottelsberghe, B.; Nysten, S.; Megally, E. (2003) Evaluation of current fiscal incentives for business R\&D in Belgium, WP-CEB 03/011, Université Libre de Bruxelles. 